\title{
Discussion on Detrital zircon geochronology of the Carboniferous Baixo Alentejo Flysch Group (South Portugal); constraints on the provenance and geodynamic evolution of the South Portuguese Zone, Journal, Vol. 172, 294-308
}

\author{
M. F. Pereira* \\ IDL/Departamento de Geociências, ECT, Universidade de Évora, Évora, Portugal \\ *Correspondence: mpereira@uevora.pt
}

Received 6 April 2015; accepted 7 August 2015

In their recent study, Rodrigues et al. (2014) attempted a provenance analysis of the Carboniferous Baixo Alentejo Flysch Group (SW Iberia), discussing variability over time in sources of South Portuguese Zone turbidites. The $\mathrm{U}-\mathrm{Pb}$ ages presented by these authors are similar to those previously obtained by Pereira et al. (2012a, 2013). A comparison of U-Pb age distributions obtained in turbidites from the two studies using the Kolmogorov-Smirnov test indicates that they are not significantly different at the $5 \%$ confidence level, increasing the statistical significance of the detrital zircon populations of each stratigraphic formation. However, the interpretations put forward in the two studies are considerably different. The most controversial of these concerns the sources of the

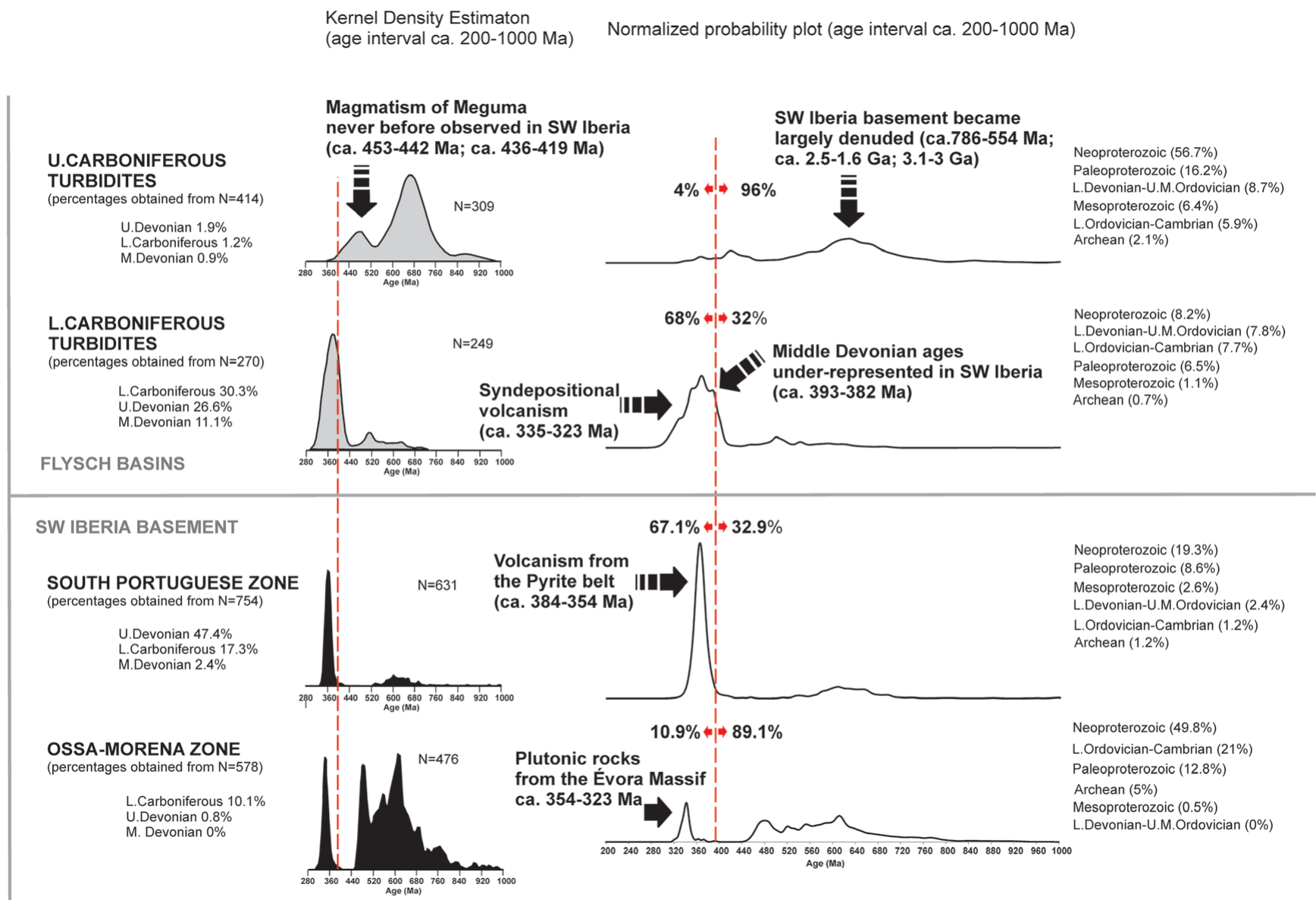

Fig. 1. Kernel density estimation and normalized probability diagrams of compiled U-Pb isotopic analyses of zircons from four groups in the age interval c. 1000-323 Ma: Lower Carboniferous turbidites (Pereira et al., 2012a, 2013; Rodrigues et al. 2014) and Upper Carboniferous turbidites (Pereira et al. 2013; Rodrigues et al. 2014) of SW Iberia, South Portuguese Zone (Rosa et al. 2008; Braid et al. 2011; Pereira et al. 2012a; Oliveira et al. 2013) and Ossa-Morena Zone (Chichorro et al. 2008; Pereira et al. 2008, 2009, 2011, 2012b, 2015; Díez Fernández et al. 2014). Plots are arranged with the flysch basins at the top and the SW Iberian basement at the bottom. Percentages were obtained considering all the data for each group. The International Chronostratigraphic Chart v2014/02 was followed to attribute radiometric ages. 